\title{
A apelação no processo civil canônico
}

\section{The canonical appeal in civil case}

João Paulo Hecker da Silva*

Resumo: O presente artigo trata do recurso de apelação no processo civil canônico, bem como da evolução histórica do instituto e da atual legislação canônica. Serão abordados temas de extrema pertinência, como a celeridade processual e a investigação de soluções adotadas no passado e em outros ordenamentos. Em razão da relevância e importância histórica do Direito canônico, que tem por finalidade não só a proteção jurídica dos fiéis, mas principalmente a salvação das almas, é que o presente estudo ficará restrito a esse instituto.

Palavras-chave: Direito Canônico - Processo canônico - Recurso de apelação - Admissibilidade da apelação.

Abstract: This article verses about the appeal in the canonical civil procedure, as well as the historical evolution of such institute and present canonical laws. Extremely pertinent topic will be addressed, such as procedural celerity and the investigation of solutions adopted in the past and in other legal orders. On the grounds of relevance and historical importance of the canon law, the purpose of which is not only the legal protection of the faithful, but mainly the salvation of souls, is that the present study is restricted to this institute.

Keywords: Canon Law; Canonical Procedure; Appeal; Admissibility of appel.

Doutor em Direito Processual pela USP. Advogado em São Paulo. jph@lucon.adv.br. 


\section{Relevância do tema}

Desde que se tem notícia do empenho da doutrina processual de tentar mitigar os efeitos deletérios do que Francesco Carnelutti denominou de tempo-inimigo ${ }^{1}$ no processo ou mesmo do dano marginal ${ }^{2}$ decorrente da lentidão do Poder Judiciário, os temas relativos à aceleração dos procedimentos e da tutela jurisdicional justa e tempestiva têm ocupado lugar de destaque nos debates jurídicos no Brasil e no mundo.

Partindo-se da premissa de que "a presteza da atividade jurisdicional constitui aspecto fundamental para o acesso à justiça” ${ }^{3}$ justamente porque o processo não pode servir de fonte de vantagens econômicas para aquele que não tem razão, como bem ressalta Paulo Henrique dos Santos Lucon, ${ }^{4}$ é que o estudo da apelação no Direito Canônico tem relevância.

Isso porque, o estudo de institutos de direito processual sob o viés histórico sempre serviu para contribuir ao debate e ao aprimoramento da tutela jurisdicional, principalmente porque, como bem lembrado por Luiz Carlos Azevedo, "sem ter a ousadia de encontrar a solução ideal para tamanha ordem de problemas, certo é que alguns caminhos podem ser determinados, como diretriz no empreendimento; e é significativo observar que, sob a visão geral no qual se colocam, acabam por retomar, em grande parte, o mesmo traçado já escolhido em outras épocas e em outras situações então ocorrentes". ${ }^{5}$

A evolução histórica do instituto da apelação no direito canônico ou mesmo da atual legislação canônica ${ }^{6}$ constituem temas de extrema

\footnotetext{
1 Diritto e Processo, Morano, 1953-1958, n. 232, pp. 353-355. Sobre essa preocupação na doutrina nacional, por todos: CÂNDIDO RANGEL DINAMARCO, A reforma da reforma, Malheiros, n. 46, pp. 90-91.

2 PIERO CALAMENDREI, "Introduzione allo studio sistematico dei provvedimenti cautelari”, Opere Giuridiche, Morano, 1983, n. 8, p. 173.

3 PAULO HENRIQUE DOS SANTOS LUCON, Eficácia das decisões e execução provisória, RT, 2000, p. 172.

4 PAULO HENRIQUE DOS SANTOS LUCON, Eficácia das decisões e execução provisória, RT, 2000, p. 172.

5 Introdução à história do Direito, 1. ed., RT, 2005, p. 319.

6 “São inúmeros os traços do Direito Canônico que aparecem em toda a seqüência dos atos processuais: o próprio emprego da palavra 'procedere', no sentido de agir, em especial
} 
pertinência nesse contexto de celeridade processual e de investigação em soluções adotadas no passado ou em outros ordenamentos. ${ }^{7}$

A esse respeito, bem ressaltam José Rogério Cruz e Tucci e Luiz Carlos Azevedo: "ademais, norteada pela eclesiologia ditada pelo Concílio Vaticano II, a comissão encarregada de rever o processo canônico, para preparação do novo Código, procurou atender à exigência de uma justiça rápida e eficiente, impregnada de equidade e, tanto quanto possível, acessível a todos. Esse ideário, em busca de um processo justo, teve ampla repercussão no âmbito dos trabalhos de elaboração legislativa da codificação canônica”. ${ }^{8}$

Baseado nas lições de Miguel Reale, como de fato estamos, no sentido de que direito é fato, valor e norma, ${ }^{9}$ é evidente que não basta

por parte do juiz: 'priores iudices ad decisionem causae possunt procedere (...)' (Decretais 1.3.3); '(...) ut iudex, cui taliter causam committimus', 'necessario libellum non exigat (...) procedere veleat (...)” (LUIZ CARLOS AZEVEDO, Introdução à História do Direito, RT, São Paulo, 2005, p. 121).

7 Veja que há ainda influência indireta do direito canônico no ordenamento jurídico brasileiro decorrente de uma influência direta nas Ordenações do Reino de Portugal. Uma das fontes do direito canônico e que também influenciou o direito português foi a Sagrada Escritura. Em vista da forte tradição católica do povo e da corte portuguesa, o direito canônico, de acordo com a Cúria de 1211, se impunha em certo período ao próprio direito régio nos tribunais civis do Reino de Portugal, muito embora sem grande efetividade. Conforme lição de Nuno J. Espinosa Gomes da Silva, essa influência ainda se faria presente em Portugal já que, "em tempos posteriores, haverá tendência em aceitar o direito canônico, subsidiariamente, sempre 'agebatur de pecato', isto é, em matérias que envolvessem pecado" (História do Direito Português - fontes de direito, 3. ed., Lisboa, Fundação Calouste Gulbenkian, 2000, p. 177). A respeito das fontes do direito canônico, confira: ARNALDO BERTOLA, "Diritto Canônico", in Novissimo Digesto Italiano, v. V, Torino, VTET, 1957, pp. 798-799; e Fernando Della Rocca, Diritto Canônico, Padova, Cedam, 1961, pp. 7-12.

8 JOSÉ ROGÉRIO CRUZ, TUCCI e LUIZ CARLOS AZEVEDO, Lições de Processo Civil Canônico, RT, 2001, São Paulo, nota dos autores, p. 7.

9 “fato, valor e norma estão sempre presentes e correlacionados em qualquer expressão da vida jurídica, seja ela estudada pelo filósofo ou o sociólogo do direito, ou pelo jurista como tal (...) a correlação entre aqueles três elementos é de natureza funcional e dialética, dada a 'implicação-polaridade existente entre fato e valor, de cuja tensão resulta o momento normativo, como solução superadora e integrante nos limites circunstanciais de lugar e de tempo (concreção histórica do processo jurídico, numa dialética de complementariedade)" (Miguel Reale, TEORIA TRIDIMENSIONAL DO DIREITO, 5. ed., 6. tiragem, São Paulo, Saraiva, 2003, p. 57). No mesmo sentido: Miguel Reale, Lições Preliminares de Direito, 27. ed., 3. tiragem, Saraiva, São Paulo, 2003, pp. 64 e ss. Especialmente p. 68: "se, como bem adverte Jackson de Figueiredo, a vida vale, sobretudo como oportunidade de aperfeiçoar-nos, o Direito, em razão de sua própria estrutura e destinação, representa uma dessas dimensões essenciais da vida”. Em termos semelhantes, assevera Ovídio A. Batista da Silva: "supondo, como a doutrina supõe, que sua constelação de conceitos seja 
simplesmente reproduzirmos normas vetustas encontradas em pesquisas históricas, nem tampouco simplesmente importarmos métodos legislativos de ordenamentos alienígenas. O trabalho do operador do direito, do hermeneuta, ou dos juristas deve ser, portanto, o de investigar soluções para aprimoramento da tutela jurisdicional. Daí que mitigar a comum repulsa acerca da historicidade do direito ${ }^{10}$ vem como reforço das medidas de aprimoramento da tutela jurisdicional. É na órbita dessa relevância metodológica que se desenvolverá nos itens a seguir o tema da apelação no direito canônico.

\section{0 processo canônico como instrumento de salvação das almas}

No processo civil já é conhecida a doutrina de CÂNDIDo RANGEL Dinamarco pela qual o processo é visto sob o viés da instrumentalidade, como meio de pacificação social com justiça. ${ }^{11}$ Ou mesmo como meio pelo qual se concretiza o comando abstrato da norma jurídica não como simples formulação da regra concreta, mas como satisfação real do direito. ${ }^{2}$

\footnotetext{
eterna e universal, não considera ela a advertência de Max Ernest Mayer de que 'os conceitos jurídicos são extraídos do processo cultural (Filosofia del derecho, 1923, Barcelona, 1937, p. 23), devendo, portanto, evoluírem e transformarem-se na medida em que evolui e transforma-se o processo histórico-cultural de cada povo" (OVÍDIO A. BAPTISTA DA SILVA, Jurisdição e execução na tradição romano-canonica, 3. ed., Forense, Rio de Janeiro, 2007, pp. 185-186).

10 "A busca de regras e princípios de validade universal e eterna, que preside nossa cultura jurídica, esta 'repulsa' pela historicidade do Direito, pode conduzir consequências espantosas como adverte Ewald, ao descobrir-se, como fizeram os juristas franceses, que, para mudar inteiramente o direito civil francês, não foi necessário mudar o Código Civil: 'desse modo, faz parte da experiência contemporânea do direito francês o facto de não ser necessário mudar o código - o Código Civil, precisamente - para que se mude o direito (p. 211). Este é o preço afinal pago pelos ordenamentos jurídicos e pelos ambiciosos sistemas doutrinários de que foi prodigioso o pensamento europeu, a partir do século XIX: a permanência do direito, a conservação indefinida de suas regras e princípios fazem-se a custo da cada vez mais completa alienação da história e dos fatos sociais" (OVÍDIO A. BAPTISTA DA SILVA, Jurisdição e execução na tradição romano-canonica, 3. ed., Forense, Rio de Janeiro, 2007, pp. 178-179).

${ }^{11}$ A instrumentalidade do processo, 10. ed., Malheiros, São Paulo, 2002.

${ }^{12}$ ANDREA PROTO PISANI, Lezione di diritto processuale civile. Napoli: Jovene, 1999, p. 756.
} 
No direito canônico o processo é também tido por seu viés instrumental..$^{13}$ Nada obstante isso, faz-se necessária uma cautela para os estudiosos do tema do processo canônico, tendo em vista seu conteúdo espiritual e sobrenatural oriundo do escopo completamente diferente daquele reservado ao processo laico. ${ }^{14}$

Como bem assevera Nino Tamassia, ${ }^{15}$ o direito canônico possui duas fontes ${ }^{16}$ de cognição: uma de direito divino (baseado nas Sagradas Escrituras - Bíblia) e outra de direito humano (baseado na lei - Corpus Iuris Canonici). ${ }^{17}$ Isso porque, o direito canônico tem por finalidade

${ }^{13}$ A respeito do viés instrumental do processo canônico EDSON LuIS SAMPEL assevera que "o direito de cada fiel merece uma proteção. Esta proteção é o processo" ("Direito processual canônico", Revista de Cultura Teológica, ano XI, n. 43, abr/jun 2003, pp. 133-142, p. 134). E mais, além de uma finalidade de garantia de proteção jurídica do fiel, constitui também um sistema de limites ao poder da Igreja (autoridade): "mais do que resolver as lides, o processo decerto é um elemento suasório na consciência da autoridade" ("Direito processual canônico", Revista de Cultura Teológica, ano XI, n. 43, abr/jun 2003, pp. 133-142, p. 134). A respeito da finalidade do Código Canônico de 1983 sob o prisma da instrumentalidade, o Papa João Paulo II fez a seguinte colocação: "como principal documento legislativo da Igreja, baseado na herança jurídico-legislativa da Revelação e da Tradição, o Código deve ser considerado instrumento indispensável para assegurar a devida ordem tanto na vida individual e social como na própria atividade da Igreja”.

${ }^{14}$ Nas palavras de Nino Tamassia, "la chiesa Cattolica apostólica Romana pressupone un diritto divino che essa stessa determina da quali fonti debba derivare, che essa unicamente interpreta e che impone l'asservanza ai fedeli" (Appunti di direitto ecclesiastico, Padova, CEDAM, 1930, p. 1).

${ }^{15}$ Appunti di direitto ecclesiastico, Padova, CEDAM, 1930, pp. 14-15.

${ }^{16}$ Ainda a respeito das fontes do direito canônico, confira: JOSÉ ANTÔNIO MARTINS GIGANTE, Instituições de Direito Canônico, vol. I, 2. ed., Braga, Esc. Tip. da Oficina de S. José, 1951, pp. 7 e ss. Na exposição de motivos do Código Canônico de 1983, o Papa João Paulo II fez a seguinte assertiva a respeito da importância da Sagrada Escritura (Bíblia) como principal fonte do direito canônico: "Cristo Senhor, com efeito, de modo algum destruiu, mas, antes, deu pleno cumprimento (cf. Mt 5,17) à riquíssima herança da Lei e dos Profetas, formada paulatinamente pela história e experiência do Povo de Deus no Antigo Testamento. Dessa forma, ela se incorporou, de modo novo e mais elevado, à herança do Novo Testamento. Embora São Paulo, ao falar sobre o mistério pascal, ensine que a justificação não se realiza pelas obras da lei, mas por meio da fé (cf. Rm 3,28; cf. Gl 2,16), não exclui, contudo, a obrigatoriedade do Decálogo (cf. Rm 13, 8-10; cf. Gl 5, 13-25; 6,2), nem nega a importância da disciplina na Igreja de Deus (cf. 1 Cor 5-6). Os escritos do Novo Testamento permitem-nos, assim, perceber mais claramente essa importância da disciplina e entender melhor os laços que a ligam mais estreitamente à índole salvífica da própria Boa Nova do Evangelho".

${ }_{17}$ A respeito das fontes do direito canônico, confira: FERNANDO DELLA ROCCA, Diritto Canônico, Padova, Cedam, 1961, pp. 7-12; ARNALDO BERTOLA, "Diritto Canônico", Novissimo Digesto Italiano, vol. V, Torino, VTET, 1957, pp. 798-799. Na exposição de motivos do Código Canônico de 1983, o Papa João Paulo II fez a seguinte assertiva a respeito da fonte 
não só a proteção jurídica dos fiéis, mas principalmente a salvação das almas. Como bem ressalta Luiz Carlos de Azevedo, "se 'o reino de Cristo não é deste mundo', a Igreja nele vive, alimentando-se de suas duas fontes, uma religiosa e outra secular (...) acima dos interesses materiais, prevalece a finalidade única, a salvação da alma”. ${ }^{18}$

Muito embora não haja qualquer disposição expressa nesse sentido no Código Canônico, ${ }^{19}$ essa profunda ligação entre o direito canônico e a ciência teológica tem fundamento nas próprias premissas em que se baseia a Igreja Católica. ${ }^{20}$ Isso porque, tal direito possui uma suprema finalidade religiosa,${ }^{21}$ já que apesar de ser de origem divina e humana, ${ }^{22}$ a lei no direito canônico é sempre de inspiração divina. ${ }^{23}$ É nessa dicotomia entre o natural e o sobrenatural que reside a dupla

primária do código e do próprio direito canônico: “outra questão que emerge é sobre a natureza do Código de Direito Canônico. Para responder devidamente a ela, cumpre recordar o antigo patrimônio de direito contido nos livros do Antigo e do Novo Testamento, de onde, como de fonte primária, emana toda a tradição jurídico-legislativa da Igreja”. 18 (LUIZ CARLOS AZEVEDO, Introdução à História do Direito, RT, São Paulo, 2005, p. 111). No mesmo sentido: Jônatas Luiz Moreira de Paula, História do Direito Processual Brasileiro, Manole, São Paulo, 2002, p. 113.

${ }_{19}$ A esse respeito José Rogério Cruz e Tucci e Luiz Carlos Azevedo citam: Pio Fedele, Pio Ciprotti, Raimundo De Penaforte e Tomás de Aquino (Lições de Processo Civil Canônico, RT, 2001, São Paulo, p. 15).

${ }^{20}$ Sobre a natureza jurídica da Igreja: FERNANDO DELLA ROCCA, Diritto Canonico, Padova, Cedam, 1961, pp. 105-106.

${ }^{21}$ Andréa Zanotti e Fulvio Orlando argumentam: "la caratteristica primaria del diritto canônico (...) é quella diessere la proiezione, la rappresentazione formale de una società religiosa" (L'Itinerario Canonistico di Giuseppe Caputo, Milano, Giuffrè, 2002, p. 118). Baseados nessa premissa é que os autores afirmam que o direito canônico está baseado ainda em sua "suprema finalità religiosa", exatamente por se configurar "come una forma che deve tradurre il meno infedelmente possibile una sostanza spirituale e religiosa" ( $p$. 118).

${ }^{22}$ Essa premissa singular do direito canônico é confirmada ainda pelos seus ideais de justiça eternos ("príncipes éternels de justice"), como pondera Pierre Andrieu-Guitrancourt (Les Principes Sociaux du Droit Cannique contemporain, Paris, Sirey, 1939, p. 12). Mais adiante o autor assevera: "l'Égise, enseignait l'abbé Perreyve (Peyroux, L'abbé Perreyve, Paris, Spes, 1933, p. 464), est un composé de temps et d'éternité... parce qu'elle est lê mariage de Dieu avec l'humanité" (p. 143).

23 "Os princípios religiosos que fundamentam o direito canônico afirmam ao mesmo tempo a necessidade de um direito profano" (PEDRO LOMBARDÍA, Lições de Direito Canônico, Loyola, São Paulo, 2008, p. 17). Pio Fedele, citando Vicenzo Del Giudice, fala do pressuposto espiritual indispensável para penetrar no significado profundo do direito canônico (“Diritto Canonico", Enciclopedia del diritto, vol. XII, Milano, Giuffrè, 1964, pp. 897). 
instrumentalidade da norma processual canônica. ${ }^{24}$ pacificar os fiéis e garantir-lhes também a salvação de suas almas. ${ }^{25},{ }^{26}$

Essa característica tem reflexos tão profundos no direito canônico que influi até na própria definição do conceito de jurisdição. Se por um lado nos costumamos no direito comum a definir jurisdição como poder no plano da soberania nacional, função nos limites das atribuições do Estado e atividade no processo, ${ }^{27}$ ou ainda como "uma das expressões do poder do Estado, que é uno", ${ }^{28}$ resta evidente que tais conceitos laicos de jurisdição não são aplicáveis ao direito canônico. ${ }^{29}$

A lei canônica e principalmente o Código Canônico estão baseados no supernatural, no fantástico, no espiritual e na fé. ${ }^{30}$ É exatamente nessa premissa teológica que se concentra o ponto nevrálgico de distinção da jurisdição canônica com a laica: não há ligação com a territorialidade nem com a atividade do poder de um Estado porque,

\footnotetext{
${ }^{24}$ Sobre a dicotomia entre o direito humano e o direito divino: ARNALDO BERTOLA, “Diritto Canonico", Novissimo Digesto Italiano, vol. V, Torino, VTET, 1957, p. 798.

${ }_{25}$ "Como bem remata o Cânone 1.752 do atual Código de Direito Canônico, a Igreja e o direito que lhe corresponde, embora sensíveis às várias transformações ocorridas no substrato social, permanecem íntegros no sentido de resguardar e preservar aquele princípio primeiro que os instruiu, fundado na fraternidade e harmonia, na equidade e solidariedade, levando sempre em conta a salvação das almas, lei suprema que impulsiona e conduz" (LUIZ CARLOS AZEVEDO, Introdução à História do Direito, RT, São Paulo, 2005, p. 123). Confira a redação do cânone 1752: "Nas causas de transferência, apliquem-se as prescrições do cân. 1747, respeitando-se a eqüidade canônica e tendo diante dos olhos a salvação das almas que na Igreja, deve ser sempre a lei suprema”.

${ }^{26}$ Com relação à questão da salvação das almas, vale verificar o que o Papa João Paulo II afirmou na exposição de motivos do Código Canônico de 1983: “exortamos, pois, todos os diletos filhos a que observem com sinceridade e boa vontade as normas propostas, na firme esperança de que refloresça a solícita disciplina da Igreja e de que, assim, sob a proteção da Beatíssima Virgem Maria, Mãe da Igreja, se promova mais e mais a salvação das almas".

${ }^{27}$ CELSO NEVES, Estrutura fundamental do processo civil, Forense, 1995, p. 28. Ver também: CÂNDIDO RANGEL DINAMARCO, Instrumentalidade do processo, 6. ed., Malheiros, nn. 9-17, pp. 77-137.

${ }^{28}$ CÂNDIDO RANGEL DINAMARCO, Instrumentalidade do processo, 6. ed., Malheiros, $\mathrm{n}$. 15, p. 115.

${ }^{29}$ A respeito do conceito e da definição de direito canônico confira: ARNALDO BERTOLA, “Diritto Canônico”, Novissimo Digesto Italiano, vol. V, Torino, VTET, 1957, pp. 796-797. No mesmo sentido em relação à definição de direito canônico: FERNANDO DELLA ROCCA, Diritto Canônico, Padova, Cedam, 1961, pp. 1-2.

30 “Elle est supernaturaliste, Dieu n’est pás seulement l'Etre supreme déistes" afirma Jean des Graviers (Le Droit Canonique, 10. édition, Paris, Presses Universitaires de France, 1967, p. 23).
} 
segundo bem pondera PEdro Lombardía, "a Igreja é um povo de ordem sobrenatural" ${ }^{31}$

Na verdade, a jurisdição canônica será exercida sempre que houver um núcleo de fiéis, ${ }^{32}$ independentemente do território em que se encontrarem, já que o exercício da fé independe de limites territoriais, nacionalidade ou qualquer outro fator de limitação físico.

Como a Igreja não é uma entidade política delimitada em seu poder por um território, ${ }^{33}$ a jurisdição canônica é exercida pelos fiéis, onde quer que se encontrem, o que denota a concepção de universalidade da jurisdição canônica. Nesse aspecto, o cânone 1.476 do Código Canônico de 1983 introduziu importante modificação na experiência jurídica canônica ao dispor que "quem quer que seja, batizado ou não, pode agir em juízo; e a parte, legitimamente demandada, deve responder".

\footnotetext{
${ }^{31}$ PEDRO LOMBARDÍA, Lições de Direito Canônico, Loyola, São Paulo, 2008, p. 19. Jean des Graviers assevera a respeito da existência de direitos supremos emanados de Deus: "Cette legislation est spirituale au sens complet du mot. Non seulement elle admet l'existence de l'ame humaine mais elle reconnaît l'existence de droits suprêmes de Dieu. Au point de vue juridique, il em resulte que Dieu est lê maitre absolu, que nul ne legifere légitimement contre lui, ni sans détenir um pouvoir dérivant de quelque façon de lui, ni en fasant fi de l'éminete dignité de la personne humaine" (Le Droit Canonique, 10. édition, Paris, Presses Universitaires de France, 1967, p. 22). Nada obstante o fato de que a questão da territorialidade seja importante para o Direito Canônico (p. ex.: mormente em casos de divisão de competências paroquiais), independentemente do território em que se encontre o fiel ou o local em que ele praticou o ato questionado, estará ele submetido à jurisdição canônica. Isso porque, para a jurisdição canônica, a competência se dá em razão da fé e não do território no qual o ato foi praticado (v. Cân. 12, § 1. As leis universais obrigam em todos os lugares a todos aqueles para os quais foram dadas).

${ }^{32}$ Com premissa na acepção da palavra, Mario Falco assevera que "diritto ecclesiastico, nel più ampio significato della parola, è complesso delle norme giuridiche, che regolano l'attività degli uomini, in quanto essi appartengono ad una colettività religiosa e mirano al reggiungimento dei fini di essa (...) il più importante fra i diritti propri delle società religiose è il diritto prodotto dalla Chiesa cattolica" (Corso di Diritto Ecclesiastico, volume primo, 2. edizione, Padova, CEDAM, 1935, p. 3).

${ }^{33}$ Segundo Jônatas Luiz Moreira de Paula, a Igreja Católica possui uma "personalidade jurídica ex ipsa divina ordinatione, com eficácia e limitação no espaço jurídico, uma vez que atua em beneficium indistinctum" (História do Direito Processual Brasileiro, Manole, São Paulo, 2002, p. 116). No mesmo sentido sobre a personalidade jurídica da Igreja Católica: ARTURO CARLO JEMOLO, Lezioni di Diritto Ecclesiastico, 3. ed., Giuffrè, Milão, 1958, pp. 212-213.
} 


\section{A impugnação da sentença e o duplo grau de jurisdição}

Como decorrência ínsita à natureza humana, o processo canônico possui a possibilidade de revisão das decisões proferidas pelos julgadores. Tal garantia representa um verdadeiro duplo grau de jurisdição, tal qual se verifica no ordenamento laico, baseada na premissa de que é possível e até mesmo comum, que os juízes profiram decisões equivocadas ou injustas. Para mitigar o mal que ocorreria a permanência no ordenamento jurídico (laico ou canônico) de uma decisão incorreta, injusta ou viciada, é que o Código Canônico previu a existência de meios de impugnação das decisões.

Tamanha foi a preocupação com a garantia de uma sentença hígida que o Código Canônico estatuiu, no cânone 1.641, §1, o duplex sententia conformis. Confira a redação: Salva a prescrição do cân. 1643, há coisa julgada: 1 - se tiverem sido dadas duas sentenças concordes entre as mesmas partes, sobre a mesma petição e pela mesma causa de demanda; $2^{\circ}$ - se a apelação contra a sentença não tiver sido apresentada dentro do tempo útil; $3^{\circ}$ - se, em grau de apelação, a instância se tiver tornado perempta ou se tiver havido renúncia a ela; $4^{\circ}$ - se tiver sido proferida sentença definitiva, contra a qual não se admite apelação, de acordo com o cân. 1629”.

Ou seja, para que uma causa levada ao Tribunal canônico ${ }^{34}$ passe em julgado, com todas as qualidades inerentes à sua imutabilidade, é necessário que duas instâncias analisem a causa. Segundo o cânone 1441: "O tribunal de segunda instância deve ser constituído do mesmo modo que o tribunal de primeira instância. Contudo, se no primeiro grau de juízo, de acordo com o cân. 1425, § 4, um único juiz proferiu a sentença, o tribunal de segunda instância proceda colegialmente”.

"Ademais, a lei canônica ocidental foi praticamente reproduzida no que se refere à sistemática recursal e ao regime da coisa julgada, exigindo também, o cânone 1.322, 1 , do Código das Igrejas orientais,

\footnotetext{
${ }^{34}$ A respeito da nomeação dos juízes canônicos de primeira e segunda instância, confira: LUCIANA CARLA CORRÊA BERTOCCO, Origens e evolução da figura do juiz, São Paulo, 2005, dissertação de mestrado perante a Pontifícia Universidade Lateranense de Roma (Instituto de Direito Canônico “Pe. Dr. Giuseppe Benito Pegoraro”), pp. 69-78.
} 
a 'dupla conforme' para sentença alcançar o trânsito em julgado, ressalvadas as causas de statu personaram". ${ }^{35}$ Conforme veremos adiante, esse princípio da dupla conforme deve ser aplicado com reservas, nada obstante constituir um norte na interpretação processual da sistemática recursal canônica. ${ }^{36}$

Uma parte da literatura já sustentou que a origem da apelação (ou dos próprios recursos) no direito canônico surgiu com Apóstolo São Paulo pleiteando apelar diretamente para o Imperador Romano César, ao se ver diante de Porcio Festo para julgamento. Essa tese, baseada em fragmento do Novo Testamento (Atos dos Apóstolos, 25.11 e 12), é refutada por RICCARDO ORESTANO ${ }^{37}$ que afirma não haver sentença alguma a ser apelada naquele caso, tendo sido a apelação à César mero ato de competência decorrente da qualidade de cidadão romano de São Paulo. ${ }^{38}$ Nada obstante FERNANDO DELLA ROCCA ${ }^{39}$ afirmar haver controvérsias acerca dessa denominação, a doutrina canônica tem por dividir os meios de impugnação da sentença canônica em ordinários e extraordinários.

Diferentemente do Código Canônico de 1917 (que previa a oposição do terceiro no ordenamento anterior), o atual código previu apenas a apelação como meio ordinário de impugnação da sentença e a restitutio in integrum e a querella nulitatis como meios extraordinários.

Como dito, o antigo Código Canônico de 1917 foi suprimido na parte em que previa a oposição de terceiro como meios de impugnação da sentença. Contudo, isso não significa que hoje o terceiro não possa insurgir-se contra decisão que lhe é desfavorável ou que interfira em sua esfera de direitos subjetivos. Isso porque, apesar de o novo Código

\footnotetext{
35 JOSÉ ROGÉRIO CRUZ e TUCCI e LUIZ CARLOS DE AZEVEDO, Lições de Processo Civil Canônico, RT, São Paulo, 2001, p. 86.

${ }^{36} \mathrm{Na}$ apelação em processo de nulidade de matrimônio, mesmo após a dupla conforme, podem as partes contrair novas núpcias desde que ingressado com a querela de nulidade. (JESÚS HORTAL, Código de Direito Canônico, 9. ed., São Paulo, Edições Loyola, 1995, trad. Conferência Nacional dos Bispos do Brasil, p. 723).

37 Riccardo Orestano, L'appelo civile in diritto romano, 2. ed., Torino, Giapichelli, 1966, p. 198 (citado por JOSÉ ROGÉRIO CRUZ e TUCCI e LUIZ CARLOS DE AZEVEDO, Lições de Processo Civil Canônico, RT, São Paulo, 2001, p. 147).

${ }^{38}$ Sobre a origem da apelação no direito romano: RICCARDO ORESTANO, "Appello (Diritto Romano)”, Novissimo Digesto Italiano, Torino, VTET, 1957, pp. 723-725.

${ }^{39}$ FERNANDO DELLA ROCCA, Diritto Canonico, Padova, Cedam, 1961, pp. 7 e ss.
} 
de 1983 haver suprimido a oposição de terceiro como meio autônomo de impugnação da sentença, permite o terceiro interessado ingressar no processo no estado em que se encontra e também valer-se de restitutio in integrum, permissões essas antes inexistentes.

Nesse prisma, vigora no direito canônico a multirrecorribilidade das decisões, já que em alguns casos a mesma parte pode manejar simultaneamente dois ou mais meios de impugnação das sentenças, como pode ocorrer, p. ex., com o manejo da apelação e da restitutio in integrum conjuntamente contra uma mesma sentença. Nesse sentido é importante diferenciar quanto à finalidade de cada meio de impugnação das sentenças. ${ }^{40}$

A apelação tem por objetivo ora a retratação, ora a reforma do julgado, constituindo por isso, o meio ordinário e clássico de impugnação das sentenças. ${ }^{41}$ Como se verá adiante e que aqui se adianta em linhas gerais, a apelação ter por inerente à sua essência o efeito devolutivo, já que devolve o conhecimento da matéria ao órgão $a d$ quem, constituindo mero prosseguimento da causa em atendimento à dupla conforme e à garantia do duplo grau de jurisdição. ${ }^{42}$

É próprio da natureza da apelação que o juiz que a julga seja de maior autoridade que o que julgou a causa em primeiro grau de jurisdição. No direito canônico, a doutrina costuma chamar o juiz que julga a apelação como “iudex superior”, como bem denota Giuseppe Olivero. ${ }^{43}$

\footnotetext{
${ }^{40}$ A respeito da natureza jurídica da sentença e da função da sua motivação no processo canônico: PAOLA BUSELLI MONDIN, Il sistema dei ricorsi e dei decreti nel processo matrimoniale canônico, Lateran University Press, Roma, 2004, pp. 67 e ss. e 83 e ss. A respeito da natureza jurídica da sentença e da função da sua motivação no processo canônico: PAOLA BUSELLI MONDIN, Il sistema dei ricorsi e dei decreti nel processo matrimoniale canônico, Lateran University Press, Roma, 2004, pp. 67 e ss. e 83 e ss.

${ }^{41}$ Confira a respeito da divisão das sentenças a respeito da matéria, da causa e da justiça: José Antônio Martins Gigante, Instituições de Direito Canônico, vol. III, 2. ed., Braga, Esc. Tip. da Oficina de S. José, 1952, p. 180.

42 "em sentido técnico, a apelação é o meio de impugnação previsto contra decisões validas mas tidas injustas pela parte que perdeu, no todo ou em parte, e consiste em um reexame da causa por parte do juiz superior para obter a reforma da primeira decisão e o reconhecimento da pretensão não conseguida em primeira instância” (MANOEL J. ARROBA CONDE, Direito Processual Canônico, 5. ed., EDIURCA-Editiones Institutum Iuridicum Claretianum, São Paulo, 2006. Trad. Martin Segú Girona, p. 649).

43 “Apello - Diritto Canonico", Enciclopedia del diritto, vol. II, Milano, Giuffrè, 1958, p. 805.
} 
A querela de nulidade tem por objetivo sempre a retratação, na medida em que tem por objetivo afastar a nulidade (sanáveis ou não - o que gera uma dupla regulamentação conforme o caso) havida na decisão. Já a restitutio in integrum tem por objetivo a ora a restituição, ora a reforma, dependendo do caso e tem por objetivo impugnar sentença injusta (mas aparentemente válida), já transitada em julgado. Diferentemente da apelação, a querela de nulidade e a restituição por inteiro não possuem efeito devolutivo porque se inicia, em ambos os casos, um processo autônomo ao anterior, substituindo-o. ${ }^{44}$

Ainda no que diz respeito à impugnação das sentenças é relevantíssimo mencionar a existência do recurso per saltum, que constitui a possibilidade de causa ser levada a conhecimento e julgamento direto pela Santa Sé (Papa). A Rota Romana, como é mais conhecida tal possibilidade, profere decisões irrecorríveis, passíveis apenas de querela de nulidade, a qual, caso tenha sido ajuizada contra uma sentença proferida pelo Papa, terá seu mérito julgado pelo Supremo Tribunal da Assinatura Apostólica (c. $1445, \S 1^{\circ}$ ).

Exatamente por contar com um sistema de controle e de impugnação das decisões é que as sentenças proferidas devem ser fundamentadas. Os motivos que levaram o julgador julgar dessa ou daquela forma devem constar de todas as decisões, na medida em que confere legitimidade à atividade cognitiva do julgador e possibilita ao sucumbente o manejo do recurso competente.

José Rogério Cruz e Tucci e Luiz Carlos Azevedo bem lecionam que "pela perspectiva da técnica processual, os fundamentos da decisão, por outro lado, permitem efetuar o controle da sentença, para a exata determinação da dimensão da ratio iudicandi, e, consequentemente, para a verificação dos limites do julgado. Assim, somente tendo ciência dos motivos é que o interessado poderá preparar as razões de recurso de modo satisfatório. E, destarte, o órgão ad quem poderá controlar com maior rigor a justiça e a legalidade dos atos decisórios impugnados". ${ }^{45}$

\footnotetext{
44 JOSÉ ROGÉRIO CRUZ E TUCCI E LUIZ CARLOS DE AZEVEDO, Lições de Processo Civil Canônico, RT, São Paulo, 2001, p. 147.

45 JOSÉ ROGÉRIO CRUZ e TUCCI e LUIZ CARLOS DE AZEVEDO, Lições de Processo Civil Canônico, RT, São Paulo, 2001, p. 140.
} 


\section{Requisitos de admissibilidade da apelação}

Como já dito, a apelação constitui um recurso ordinário por excelência porque devolve a uma instância superior o conhecimento de uma matéria já decidida por uma instância inferior. Trata-se do efeito devolutivo da apelação canônica. Fernando Della Rocca trata do assunto afirmando que, em essência, a apelação não gera um novo processo, mas tão-somente devolve a cognição do mérito da causa ao Tribunal ad quem. ${ }^{46}$

No que se refere à admissibilidade dos recursos vale mencionar a existência de pressupostos objetivos (pluralidade, recorribilidade da decisão e tempestividade) e aqueles pressupostos subjetivos (legitimidade e interesse recursal).

O recurso de apelação é cabível apenas contra as sentenças definitivas ou contra a sentença interlocutória com força definitiva. Isso porque, quer a lei canônica que a instância superior se manifeste apenas e tão somente com relação às questões ou casos julgados em primeira instância que não possam ser objeto de revisão pelo MM. Juízo a quo. Trata-se de uma opção lógica, o que demonstra que o processo canônico também é regido pela regra da utilidade dos atos processuais e pela a economia processual.

O interesse decorre, evidentemente, da derrota e da sucumbência nos pedidos. Hodiernamente os recursos são destinados àqueles que, se sentindo prejudicados com a decisão, possam questionar sua justiça perante uma instância superior ${ }^{47}$ A ideia de prejuízo não se coaduna com o vencedor da ação já que, ao deparar-se com uma decisão que atendeu a seus pedidos, ilógica a posição de pretender sua revisão.

De qualquer forma, a apelação será sempre cabível das sentenças definitivas. A respeito da definição dos pronunciamentos do juiz, confira a lição de Aloísıo Surgik: "a sentença é a pronúncia legítima pela qual o juiz resolve a causa proposta pelos litigantes e tratada judicialmente: chama-se interlocutória quando dirime uma causa

\footnotetext{
${ }^{46}$ FERNANDO DELla ROCCA, Diritto Canônico, Padova, Cedam, 1961, p. 452.

47 JUAN JOSÉ GARCÍA FAÍLDE, Nuevo Derecho Procesal Canonico, 3. ed., Salamanca, Publicaciones Universidad Pontificia Salamanca, 1995, p. 263.
} 
incidental, e definitiva, quando a principal. As demais decisões do juiz se chamam decretos". ${ }^{8}$

Veja que é possível conferir-se força definitiva à sentença interlocutória ${ }^{49}$, seja nos casos em que se nega ao autor a capacidade de exercitar seu direito, ou ao juiz sua competência, seja quando houver prejulgamento da causa, por exemplo, ao declarar falso um documento em que se apoia a questão..$^{\circ}$ Com base no antigo Código Canônico "la sentenza emanata sulla base del giuramento decisório è inappellabile, ai sensi del cânone 1880 (...) essa ha, duque, valores e forza di cosa giudicata, come da inequivoco dettato del canone 1902, n. 3 ". ${ }^{51}$

A respeito da inadmissibilidade da apelação pela natureza da decisão recorrida, conforme a redação do cânone 1629, não cabe apelação: ${ }^{52}$ das decisões do Sumo Pontífice (Papa), já que o Papa ocupa o mais alto grau na hierarquia da Igreja Católica, tampouco das decisões do Supremo Tribunal da Assinatura Apostólica, porque, como visto, são elas tiradas normalmente das querelas de nulidade ajuizadas contra as decisões do Sumo Pontífice.

Também não será cabível apelação das sentenças viciadas de nulidade, porque contra esses vícios cabe a querela nulitatis, a menos que a apelação tenha sido interposta juntamente no exercício da faculdade

\footnotetext{
48 ALOÍSIO SURGIK, Compêndio de Direito Processual Canônico, Edições Livro é Cultura, Curitiba, 1988, pp. 47-48.

49 "Nonostante la mancata, espessa previsione normativa, i complementatori hanno concordemente ritenuto cho possa deferirsi giuramento decisório 'in quolibet litis momento et statu. Il deferimento è, cioè, possibile non solo durante tuto lo svolgimento della causa in primo grado, ma anche durante la fase dell'appello ed il período antecedente all'appello, ma successivo all'emissione della sentenza" (MASSIMO JASSONI, Il giuramento - profili di uno studio sul processo di secolarizzazione dell'intituto nel diritto canonico, Milano, Giuffrè, 1999, pp.199-200).

${ }^{50}$ ALOÍSIO SURGIK, Compêndio de Direito Processual Canônico, Edições Livro é Cultura, Curitiba, 1988, p. 48.

${ }^{51}$ MASSIMO JASSONI, Il giuramento - profili di uno studio sul processo di secolarizzazione dell'intituto nel diritto canonico, Milano, Giuffrè, 1999, p. 204.

${ }^{52}$ No mesmo sentido com relação às hipóteses de inadmissibilidade do recurso de apelação: MANOEL J. ARROBA CONDE, Direito Processual Canônico, 5. ed., EDIURCA-Editiones Institutum Iuridicum Claretianum, São Paulo, 2006. Trad. Martin Segú Girona, pp. 652-653. No mesmo sentido a respeito das hipóteses de inadmissibilidade do recurso de apelação: GIUSEPPE OLIVERO, “Apello - Diritto Canonico”, Enciclopedia del diritto, vol. II, Milano, Giuffrè, 1958, pp. 805-806; JUAN JOSÉ GARCÍA FAÍLDE, Nuevo Derecho Procesal Canonico, 3. ed., Salamanca, Publicaciones Universidad Pontificia Salamanca, 1995, p. 265.
} 
da multirrecorribilidade das decisões canônicas; das sentenças transitadas em julgado, já que nesses casos o meio de impugnação correto é a restituição por inteiro; das sentenças interlocutórias ou decretos sem caráter definitivo, uma vez que a definitividade é pressuposto lógico para abertura da via do duplo grau de jurisdição.

Segundo bem pondera Fernando Della Rocca, ${ }^{53}$ a noção de apelação é determinada pelo princípio do duplo grau de jurisdição. Nesse sentido o cânone 1618 é enfático em dispor que cabe recurso apenas com relação às sentenças delfinitivas, as sentenças interlocutórias em caráter definitivo e decretos de natureza decisória; das sentenças interlocutórias e decretos decisórios proferidas em causas em que o direito determina que devam ser decididas com a máxima rapidez, uma vez que, apesar de possuírem caráter definitivo, a sistemática processual canônica houve por bem privilegiar a celeridade em detrimento da certeza; bem como em algumas hipóteses previstas em leis extravagantes, por opção legislativa.

Por fim, incabível será a apelação das decisões da Rota Romana videntibus ominibus (decisões proferidas pelo plenário rotal, composto por todos os integrantes do tribunal), porque nesse caso a parte opta pelo apelo direto ao Papa em detrimento do Tribunal de segunda instância. Segundo o cânone 1444, §1º, n. 1, o Tribunal da Rota Romana julga em segunda instância os recursos de apelação interpostos das sentenças de primeira instancia, ou seja, nesses casos o Tribunal de segunda instância não julga a apelação, já que o recurso é interposto per saltum do Tribunal do Bispo à Rota Romana; e das sentenças de juiz delegado da Santa Sé, com clausula apellatione remota, por opção legislativa.

Quanto à legitimidade para interpor a apelação (aqui configurada no binômio interesse-utilidade) é importante frisar que estão autorizados a manejar esse recurso a parte, terceiro prejudicado para afastar prejuízo decorrente da sentença, promotor de justiça e o curador do vínculo (principalmente nas causas matrimoniais), nos termos do cânone 1628. Vale ressaltar que, havendo alteração subjetiva da lide, aquele que passar a possuir a qualidade de parte poderá recorrer. E

${ }^{53}$ FERNANDO DELlA ROCCA, Diritto Canonico, Padova, Cedam, 1961, p. 453. 
mais, de acordo com o cânone 1628, §2² se a obrigação for solidária ou o objeto indivisível, a apelação de um (ou contra um) litisconsorte aproveita aos demais. ${ }^{54}$ Assim, havendo litisconsortes no recurso de apelação e não dispondo a sentença de modo diverso, haverá divisão pro rata das custas e despesas entre os litisconsortes, conforme assevera José Antônio Martins Gigante.

O prazo para interposição do recurso de apelação é de 15 dias contados da intimação da parte da sentença, consoante prescreve o cânone $1630, \S 1^{\circ}$. Caso o recurso seja interposto fora desse prazo será considerado intempestivo.

O Código Canônico vigente inovou nessa parte porque ampliou o prazo da apelação, que antes era de dez dias, para quinze dias. A contagem do prazo é em dias úteis ${ }^{55}$ e não corridos, de forma que mantida a peremptoriedade do prazo..$^{6}$ Isso porque, segundo alerta Fernando Della Rocca, seu transcurso gera a decadência não sanável do direito de impugnar a sentença. ${ }^{57}$

Mesmo sendo peremptório este prazo para apelar, ${ }^{58}$ o defensor do vínculo, nas causas em que deve apelar por preceito legal (anulação de

\footnotetext{
${ }^{54}$ No mesmo sentido a respeito do aproveitamento pelo litisconsorte em casos de apelação de uma das partes em causa em que o objeto é indivisível: JOSÉ ANTÔNIO MARTINS GIGANTE, Instituições de Direito Canônico, vol. III, 2. ed., Braga, Esc. Tip. da Oficina de S. José, 1952, p. 193. A respeito do aproveitamento do recurso de apelação pelo litisconsorte que não recorreu no caso de o objeto da ação ser incindível: GIUSEPPE OLIVERO, "Apello - Diritto Canonico”, Enciclopedia del diritto, vol. II, Milano, Giuffrè, 1958, p. 805.

${ }^{55}$ Os quinze dias de prazo para apelar são úteis e não corridos. PEDRO LOMBARDIA e JUAN IGNACIO ARRIETA, Código de Direito Canônico - edição anotada, 2. ed., Braga, Tip. da Empresa do Diario do Minho, 1997, trad. José A. Marques, p. 1221.

${ }^{56}$ A respeito da natureza peremptória do prazo da apelação, confira: GIUSEPPE OLIVERO, “Apello - Diritto Canonico", Enciclopedia del diritto, vol. II, Milano, Giuffrè, 1958, p. 804; ALOÍSIO SURGIK, Compêndio de Direito Processual Canônico, Edições Livro é Cultura, Coritiba, 1988, p. 72.

${ }^{57}$ FERNANDO DELla ROCCA, Diritto Canônico, Padova, Cedam, 1961, p. 453. O prazo da apelação é improrrogável: PEDRO LOMBARDIA e JUAN IGNACIO ARRIETA, Código de Direito Canônico - edição anotada, 2. ed., Braga, Tip. da Empresa do Diario do Minho, 1997, trad. José A. Marques, pp. 1220-1221.

${ }^{58}$ O prazo da apelação é improrrogável: PEDRO LOMBARDIA e JUAN IGNACIO ARRIETA, Código de Direito Canônico - edição anotada, 2. ed., Braga, Tip. da Empresa do Diario do Minho, 1997, trad. José A. Marques, pp. 1220-1221.
} 
matrimônio), tem de fazê-lo mesmo que expirado o prazo, consoante a Instr. Provida, art. 217, $\$ 1^{0} .{ }^{59},{ }^{60}$

Ressalte-se que a intimação para apelar pode ocorrer de diversas formas, tais como a intimação das partes no próprio tribunal, a notificação das partes de que a sentença já está disponível em cartório para consulta ou ainda por meio de envio de correspondência com aviso de recebimento. ${ }^{6 \mathrm{I}}$

A apelação é sempre interposta perante o juiz que proferiu a decisão, nos termos do cânone $1630, \$ 1^{\circ}$ A interposição do recurso de apelação perante o juiz que proferiu a sentença também foi uma das regras mantidas pelo Código Canônico de $1983 .{ }^{62}$

De qualquer forma, não podendo ser interposta por meio de petição escrita, pode a parte interpô-la oralmente, com a imediata redução a termo pelo notário em cartório na presença da parte. ${ }^{63}$ Nesses termos confira a doutrina: "se a sentença é lida publicamente, a apelação pode ser feita oralmente, perante o juiz sentado no tribunal, e o atuário a reduzirá imediatamente a escrito. Do contrário, a

\footnotetext{
${ }^{59}$ ALOÍSIO SURGIK, Compêndio de Direito Processual Canônico, Edições Livro é Cultura, Curitiba, 1988, p. 72.

${ }^{60}$ A respeito da atuação específica do defensor do vínculo nos processos matrimoniais e na atual legislação, confira: José de Ávila Cruz, A evolução histórica do processo de nulidade matrimonial e a figura jurídica do defensor do vínculo, São Paulo, 2001, dissertação de mestrado perante a Pontifícia Faculdade de Teologia Nossa Senhora da Assunção (Instituto de Direito Canônico “Pe. Dr. Giuseppe Benito Pegoraro”), pp. 55-79.

61 "A publicação da sentença pode ser feita de três modos: a) citando as partes para que ouçam a sentença a ser lida pelo juiz sentado no tribunal; b) notificando as partes de que a sentença se acha na chancelaria do tribunal e que podem lê-la e extrair cópia da mesma; c) transmitindo às partes (onde assim o uso permitir) uma cópia da sentença através do correio público, desde que as leis e condições do lugar ofereçam garantia quanto à acusação do recebimento" (ALOÍSIO SURGIK, Compêndio de Direito Processual Canônico, Edições Livro é Cultura, Curitiba, 1988, p. 51).

${ }^{62}$ G. P. SINOPOLI DI GIUNTA, Sinopsi del codice di diritto Canônico, Torino-Roma, Cav. Pietro Marietti Editre, 1920, p. 190.

${ }^{63}$ No mesmo sentido: ALOÍSIO SURGIK, Compêndio de Direito Processual Canônico, Edições Livro é Cultura, Curitiba, 1988, p. 72: "a apelação é interposta perante o juiz que proferiu a decisão, no prazo peremptório de quinze dias úteis contados da publicação da sentença. Pode também ser feita oralmente, redigindo-a o notário diante do próprio apelante (c. 1630, 1633)”. A apelação tem de ser escrita, mas permite-se sua interposição na forma oral, tendo o notário que reduzir a termo as razões do apelante: PEDRO LOMBARDIA e JUAN IGNACIO ARRIETA, Código de Direito Canônico - edição anotada, 2. ed., Braga, Tip. da Empresa do Diario do Minho, 1997, trad. José A. Marques, p. 1221.
} 
apelação há de se fazer por escrito, salvo nos casos em que o apelante não sabe ou não pode escrever (c. 1882), devendo, de qualquer forma, reduzir-se a escrito pelo notário" ${ }^{64}$

Interposta a apelação, ela se processa no prazo de 30 dias ( $a d$ prosequendum), contados da interposição. ${ }^{65}$ Esse prazo é dilatório podendo, portanto, o juiz dilatá-lo, nos termos do cânone 1633.

Para que ocorra o prosseguimento da apelação, a parte deve provocar a intervenção do juiz do tribunal de segunda instância. Essa provocação deve conter pedido expresso de correção da sentença apelada, as razões para reforma da sentença apelada, bem como deve se fazer juntar cópia dela própria. ${ }^{66}$ Como bem afirma Aloísio Surgik a respeito da dilação do prazo de 30 dias, "se a parte não puder obter do tribunal a quo cópia da sentença impugnada, dentro de tempo útil, neste ínterim, não decorrem prazos; o impedimento deve ser comunicado ao juiz de apelação que, por preceito, deve impor ao juiz a quo o cumprimento de seu dever (c. 1634)". ${ }^{67}$

Se o recurso for admitido, deve ser remetido à instancia superior para julgamento. Se houver algum incidente sobre o direito de se apelar, a controvérsia deve ser decidida pelo tribunal segundo as regras do processo contencioso oral, consoante estatuído no cânone $1631 .{ }^{68}$

É no tribunal superior que as partes apresentam cópia das razões por escrito, juntamente com a cópia da decisão recorrida, estando disposto no cânone $1634, \S 3^{\circ}$, que quem providencia a remessa do recurso de apelação ao Tribunal ad quem é o Tribunal a quo.

\footnotetext{
${ }^{64}$ ALOÍSIO SURGIK, Compêndio de Direito Processual Canônico, Edições Livro é Cultura, Curitiba, 1988, p. 49.

${ }^{65}$ A prossecução da apelação ou a sua formalização perante o Tribunal ad quem tem o prazo de um mês. PEDRO LOMBARDIA e JUAN IGNACIO ARRIETA, Código de Direito Canônico - edição anotada, 2. ed., Braga, Tip. da Empresa do Diario do Minho, 1997, trad. José A. Marques, p. 1222.

${ }^{66}$ Juntamente com os requisitos intrínsecos do escrito de apelação o apelante deve fazer acompanhar copia da sentença apelada, autenticada com assinatura do notário (c. 1437 e c. 1474, par 1). PEDRO LOMBARDIA e JUAN IGNACIO ARRIETA, Código de Direito Canônico - edição anotada, 2. ed., Braga, Tip. da Empresa do Diario do Minho, 1997, trad. José A. Marques, p. 1223.

${ }^{67}$ ALOÍSIO SURGIK, Compêndio de Direito Processual Canônico, Edições Livro é Cultura, Curitiba, 1988, p. 72.

${ }^{68}$ Cân. 1631: "Se surgir alguma questão sobre o direito de apelar, julgue-a, com a máxima rapidez, o tribunal de apelação, conforme as normas do processo contencioso oral”.
} 
Sob a égide da legislação anterior, havia a pena de deserção do recurso de apelação caso não houvesse provocação no tribunal. ${ }^{69}$ Essa regra foi mantida na atual legislação, a qual prevê a deserção da apelação se transcorrer in albis o prazo para interpor o recurso de apelação ou para prosseguir perante o Tribunal ad quem. ${ }^{70}$

Com relação ao prazo de prosseguimento perante a segunda instância, a doutrina costuma denominar de "caducidade de instância". Isto é, segundo a lição de Aloísio Surgik:

sem que haja qualquer impedimento que obste, não se pratica durante dois anos, no tribunal de primeira instância, ou durante um ano, no grau de apelação, ato algum processual, caduca a instância e, no segundo caso, a sentença impugnada pela apelação passa a ser coisa julgada (c. 1736). ${ }^{71}$

Por outro lado, de acordo com o cânone 1525, se ocorrer a renúncia ao direito de recorrer ou desistência do recurso de apelação, o recorrente fica responsável pelo pagamento das custas e despesas processuais.

Veja que não é possível inovar no recurso de apelação, de modo a introduzir fato novo para alterar a causa de pedir ou mesmo modificar a argumentação jurídica utilizada perante o Tribunal de primeiro grau. O cânone $1639, \S 1^{\circ}$ assim dispõe. ${ }^{72}$

${ }^{69}$ G. P. SINOPOLI DI GIUNTA, Sinopsi del codice di diritto Canônico, Torino-Roma, Cav. Pietro Marietti Editre, 1920, p. 190.

70 "Declara-se deserta a apelação se não se cumprem os prazos fatais assinalados nos c. 1630 e 1633" (interposição, 30 dias para prosseguir no Tribunal ad quem). PEDRO LOMBARDIA e JUAN IGNACIO ARRIETA, Código de Direito Canônico - edição anotada, 2. ed., Braga, Tip. da Empresa do Diario do Minho, 1997, trad. José A. Marques, pp. 1220-1221. ${ }^{71}$ ALOÍSIO SURGIK, Compêndio de Direito Processual Canônico, Edições Livro é Cultura, Curitiba, 1988, p. 51.

${ }^{72}$ No mesmo sentido em não se admitir inovação da causa petendi no recurso de apelação: MANOEL J. ARROBA CONDE, Direito Processual Canônico, 5. ed., EDIURCA-Editiones Institutum Iuridicum Claretianum, São Paulo, 2006. Trad. Martin Segú Girona, pp. 650-651. Contudo, o mesmo autor faz a ressalva na p. 663 de que as exceções não apresentadas em primeiro grau podem ser apresentadas em grau de recurso. Também pela impossibilidade de se inovar na apelação: PEDRO LOMBARDIA e JUAN IGNACIO ARRIETA, Código de Direito Canônico - edição anotada, 2. ed., Braga, Tip. da Empresa do Diario do Minho, 1997, trad. José A. Marques, p. 1226. 
Contudo, nas apelações tiradas de demandas de anulação de casamento essa possibilidade é permitida, nos termos do cânone 1683, sendo que o Tribunal ad quem julgaria a causa nos termos do tribunal inferior.

Isso porque, quando o recurso pretender a reabertura da causa a respeito do estado das pessoas e essa questão já houver sido decidida por duas decisões conformes, a apelação será recebida no efeito devolutivo apenas, sem o suspensivo, nos termos do cânone 1644, §2 .

Determinadas situações nunca transitam em julgado. É o caso das causas a respeito do estado das pessoas, assim entendido como as causas referentes à sagrada ordenação, ao vínculo matrimonial, à profissão religiosa etc.

Contudo, o trânsito em julgado ocorrerá sempre que houver a dupla conforme, consistente na prolatação de duas sentenças concordes a respeito do mesmo caso. Ou seja, julgada a apelação no tribunal de segunda instância mantendo a sentença, ocorre o trânsito em julgado; Também ocorrerá o trânsito em julgado com a declaração de intempestividade do recurso de apelação, em caso de renúncia da apelação, perempção, caducidade de instância. ${ }^{73}$ Veja que o direito de impugnar a sentença se perde também com a sua aceitação tácita ou expressa, total ou parcial, pela parte, como bem ressalta Fernando Della Rocca; ${ }^{74}$ Por fim, se houver sido proferida sentença definitiva contra a qual não cabe apelação (como em determinados casos de urgência) também ocorrerá o trânsito em julgado.

Se ocorrer a dupla conforme em casos sobre estado das pessoas, a qualquer tempo pode-se interpor o recurso de apelação apresentando as novas provas ou argumento, “dentro do prazo peremptório de 30 dias a contar da proposição da impugnação”. ${ }^{75} \mathrm{E}$ mais,

antes que as atas dos depoimentos testemunhais sejam publicadas, as testemunhas, mesmo depois de inquiridas, poderão ser novamen-

\footnotetext{
${ }^{73}$ A renúncia explícita à apelação é causa de perempção de instância (MANOEL J. ARROBA CONDE, Direito Processual Canônico, 5. ed., EDIURCA-Editiones Institutum Iuridicum Claretianum, São Paulo, 2006. Trad. Martin Segú Girona, p. 658).

${ }^{74}$ FERNANDO DELLA ROCCA, Diritto Canonico, Padova, Cedam, 1961, p. 453.

${ }^{75}$ ALOÍSIO SURGIK, Compêndio de Direito Processual Canônico, Edições Livro é Cultura, Curitiba, 1988, pp. 73-74
} 
te submetidas a exame, a pedido das partes ou de ofício, desde que ao juiz pareça necessário ou útil, e contanto que não haja perigo algum de conluio ou corrupção (c. 1781). $7^{6}$

O tribunal, porém, no prazo de um mês desde a apresentação das novas provas e argumentos, deve decidir, por decreto, se a nova proposição da causa deve ou não ser admitida. Esse recurso, como pondera Aloísıo Surgik, todavia, não suspende a execução da sentença, a não ser que a lei determine o contrário ou o tribunal de apelação ordene a suspensão (c. 1644, 1650, $\$ 3^{\circ}$ ).77

O recurso de apelação será sempre recebido no duplo efeito, devolutivo e suspensivo, já que o cânone 1638 expressamente prevê a suspensão da execução da sentença apelada enquanto não julgado o recurso. Além do efeito devolutivo, todas as apelações, excetuando-se as que se referem ao estado das pessoas, têm efeito suspensivo. ${ }^{78}$ Por fim, cabe a reformatio in pejus, característica que remonta desde o Decreto de Graciano, que por sua vez reproduziu a parte final da constituição de Dioclesiano e Maximiniano (C.7.62.6).

\section{Recurso de apelação adesivo}

No que se refere ao recurso adesivo ou incidental, o cânone 1637, $\S 3^{\circ}$ prevê seu cabimento. O prazo para interposição da apelação adesiva é de 15 dias da intimação da apelação principal.

Entretanto, seu cabimento é restrito às hipóteses em que um recurso não genérico for interposto, ou seja, recurso há de ser parcial focado em alguns dos capítulos da sentença apelada. Assim, o apelado, nessa hipótese, pode apelar adesivamente das partes que lhe foram desfavoráveis.

\footnotetext{
${ }^{76}$ ALOÍSIO SURGIK, Compêndio de Direito Processual Canônico, Edições Livro é Cultura, Curitiba, 1988 , p. 51.

${ }_{77}$ ALOÍSIO SURGIK, Compêndio de Direito Processual Canônico, Edições Livro é Cultura, Curitiba, 1988, pp. 73-74.

${ }^{78}$ ALOÍSIO SURGIK, Compêndio de Direito Processual Canônico, Edições Livro é Cultura, Curitiba, 1988, p. 72.
} 
O recurso principal define a sorte do adesivo, seguindo a máxima de que o acessório segue o principal. Ou seja, caso o recurso principal não seja conhecido por ausência de qualquer de seus requisitos de admissibilidade, p.ex., intempestividade da apelação ou ausência de legitimidade, a apelação adesiva também não será conhecida.

Mas nem sempre ocorrerá o não conhecimento do recurso adesivo quando o principal não for processado. Exceção à regra é a hipótese de haver renúncia ao recurso (desistência). Nesse caso o recurso adesivo é convertido em recurso principal. No mesmo sentido, Fernando Della Rocca sustenta a inexistência da perda de objeto da apelação adesiva caso haja desistência da apelação principal. ${ }^{79}$

Em caso de sucumbência recíproca não cabe recurso adesivo porque a apelação genérica possui uma prerrogativa do benefício comum da apelação genérica, que aproveita a ambos os litigantes. $\mathrm{O}$ cânone 1637, §1 ${ }^{\circ}$ afirma que "a apelação feita pelo autor vale também para o demandado, e vice-versa". ${ }^{80}$

Nada obstante a definitividade da sentença nesse caso, poderia a parte recorrer à restitutio in integrum para rescindir a sentença? A questão é controversa, mas Massimo Jassoni assevera, com base em lição de Carnelutti, que é possível já que

alla base della riflessione è, in ogni caso, la aequitas canônica non scripta, ovvero quel criterio fondamentale che nell'ordinamento canônico coincide con la 'rinuncia all'ingiustizia, al disconoscimento degli altrui diritti', con 'il ritorno alla verità' (Fedele, La revocabilità del giuramento in diretto canônico, in Scritti giuridici in onore di Francesco Carnelutti, IV, Padova, 1950, p. 498). ${ }^{81}$

\footnotetext{
${ }^{79}$ FERNANDO DELLA ROCCA, Diritto Canonico, Padova, Cedam, 1961, p. 453.

80 "A apelação é a forma típica do processo de reparação e comporta um reexame incondicionado da controvérsia tratada em primeiro grau” (MANOEL J. ARROBA CONDE, Direito Processual Canônico, 5. ed., EDIURCA-Editiones Institutum Iuridicum Claretianum, São Paulo, 2006. Trad. Martin Segú Girona, p. 649).

${ }^{81}$ MASSIMO JASSONI, Il giuramento - profili di uno studio sul processo di secolarizzazione dell'intituto nel diritto canonico, Milano, Giuffrè, 1999, p. 205.
} 


\section{Procedimento do recurso de apelação}

Distribuído o recurso de apelação no Tribunal de segunda instância,$^{82}$ o Presidente da turma julgadora designa data de julgamento, que poderá ocorrer fora da sede do tribunal, caso assim seja aconselhável diante da natureza da causa (C. $1609, \$ 1^{\circ}$ ). É importante salientar que a sessão de julgamento do recurso corre em segredo, a portas fechadas, em regime de publicidade restrita às partes interessadas. Confira a doutrina: "seguindo a linha de coerência no que diz respeito ao caráter secreto do processo, o direito canônico prescreve que durante a instrução das causas perante o tribunal, deve desocupar a sala todos aqueles que sejam alheios ao processo, permanecendo unicamente os que o juiz considere necessários para a tramitação do mesmo (c. 1640), estabelecendo-se também que as partes não podem assistir ao depoimento das testemunhas, a não ser que o juiz haja por bem admiti-las (c. 1771)". ${ }^{83}$ Isso porque, ao direito canônico interessa a solução da causa apenas aos diretamente interessados, geralmente autor e réu na demanda.

A questão do segredo é amplamente abordada pela doutrina. Segundo Aloísio Surgik, esse dever é de ofício e se estende a todos que de alguma forma participam do processo, desde juízes até notários. ${ }^{84}$ Esse

\footnotetext{
${ }^{82}$ No direito matrimonial, sob a égide do direito anterior, a apelação também era interposta perante o juiz a quo e processada e julgada por um juiz superior (cc. 1887 e 1883) (MARIO FALCO, Corso di Diritto Ecclesiastico, volume primo, 2. edizione, Padova, CEDAM, 1935, p. 303).

${ }^{83}$ ALOÍSIO SURGIK, Compêndio de Direito Processual Canônico, Edições Livro é Cultura, Curitiba, 1988, p. 51.

${ }^{84}$ ALOÍSIO SURGIK, Compêndio de Direito Processual Canônico, Edições Livro é Cultura, Curitiba, 1988, p. 50: "o segredo de ofício impõe-se sempre aos juízes e aos auxiliares do tribunal em todo juízo criminal e no contencioso, o que se impõe quando da revelação de algum ato processual poderia seguir-se algum prejuízo às partes, estando perpetuamente obrigados a guardar segredo inviolável acerca da discussão sustentada no tribunal colegiado antes de pronunciar a sentença, assim como dos diferentes votos e opiniões ali emitidos (c. 1623). Pode ainda o juiz exigir das testemunhas, dos peritos, das partes, e de seus advogados ou procuradores o juramento de guardar segredo, sempre que a natureza da causa ou das provas seja tal que, pela divulgação dos atos ou das provas, ocorra perigo à fama de outros, ou se dê ocasião a discórdias, ou resulte escândalo ou qualquer outro incômodo parecido (c. 1623, §3º”.
} 
sigilo, que é perpétuo como aponta José Antônio Martins Gigante, ${ }^{85}$ gera consequências graves como castigos e multas. ${ }^{86}$

Cada juiz, que terá estudado o caso com antecedência, prepara seu voto, independentemente do voto dos demais. Note-se que cada julgador comparece à sessão de julgamento tendo elaborado seu voto em segredo, não tendo conhecimento do voto dos demais. Cada julgador então emite seu voto por escrito, procedendo à sua leitura, não sem antes invocar o nome de Deus. Os votos de cada um dos julgadores então são juntados aos autos e só então são iniciados os debates acerca da causa por ordem do Presidente, caso haja necessidade ou divergência entre os julgadores.

É possível adiar a sessão de julgamento por uma semana, caso haja necessidade de reexame mais acurado da causa por algum dos julgadores acerca de algum novo ponto de vista advindo do debate. Adiada a sessão, o recurso de apelação deve obrigatoriamente ser julgado na sessão seguinte (C. 1609 , $\$ 5^{\circ}$, primeira parte). 0 adiamento da sessão de julgamento pode ainda ocorrer para complementação da instrução por meio de produção de outras provas ou mesmo de complementação daquelas já produzidas, desde que de acordo com o Cânone 1600 ( $c f r$. C. 1609, §5º, segunda parte).

Durante a discussão do recurso na sessão de julgamento é possível que os julgadores, em razão da argumentação travada, mudem seu voto quantas vezes forem necessárias para o deslinde da causa e para convencimento de cada um. Depois de encerrados os debates, o Presidente determina a redação do dispositivo da sentença, sendo o relator responsável pela redação com todos os requisitos do cânone 1611. Por isso, a mudança de voto dos juízes pode ocorrer até o encerramento da sessão e a lavratura do dispositivo, quando evidentemente

\footnotetext{
${ }^{85}$ Instituições de Direito Canônico, vol. III, 2. ed., Braga, Esc. Tip. da Oficina de S. José, 1952, p. 45.

86 "Os juízes que tiverem a ousadia de quebrantar a lei do segredo ou comunicar de qualquer forma a outros os atos secretos, estão sujeitos a ser castigados com multa e outras penas, sem exclusão da privação do ofício, conforme seja a gravidade da culpa, e sem prejuízo do que dispõem os estatutos particulares que regulam penas mais graves (c. $1625, \S 2^{\circ}$ )" (ALOÍSIO SURGIK, Compêndio de Direito Processual Canônico, Edições Livro é Cultura, Curitiba, 1988, p. 50).
} 
a causa estará julgada, porque é impossível reverter-se o julgamento depois de finalizado.

Contudo, o Código Canônico permite ao julgador inconformado com a decisão colegiada que remeta suas conclusões à instância superior, a fim de que o resultado de julgamento seja ratificado ou retificado. Trata-se do permissivo estatuído no cânone 1609, §4: "Durante a discussão, porém, é lícito a cada um modificar sua conclusão inicial. O juiz que não quis aceder à decisão dos outros pode exigir que, se houver apelação, suas conclusões sejam transmitidas ao tribunal superior”.

A respeito do procedimento é interessante notar ainda a preocupação com a celeridade do processo canônico. ${ }^{87}$ A relevância do tema para os canonistas é tão grande que valeu até dispor no cânone 1.453 que “os juízes e os tribunais cuidem que, salva a justiça, as causas se concluam quanto antes e que, no tribunal de primeira instância, não se protraiam mais de um ano, e no tribunal de segunda instância, mais de seis meses”. A princípio, portanto, o julgamento do recurso de apelação não ultrapassa os seis meses de tramitação, contados desde a distribuição do recurso no Tribunal de segunda instância até seu julgamento.

Como verdadeiro auxiliar da justiça, o notário (vulgo escrevente), tem como função reduzir a termo a maior parte dos atos processuais, principalmente aquele decorrentes das audiências, procedimentos de julgamento e demais atos de assentamento. Interessante notar, nesse aspecto, a afirmação de EdSON LuIz SAMPEL no sentido de que o notário é criação genuína do direito canônico. ${ }^{88}$

\section{Conclusão}

Como dito no início, os acalorados debates acerca da dicotomia certeza $\mathrm{x}$ celeridade, tem ocupado bastante os juristas modernos. Do

\footnotetext{
${ }^{87}$ A respeito da justa duração do processo canônico, com o elenco dos motivos que o autor aponta como responsáveis pela dilação da duração do processo, confira: FRANCESCO D’OSTILIO, I Processi Canonici - Loro giusta durata, Roma, Edizioni Dehoniane, pp. 88-91. ${ }^{88}$ EDSON LUIZ SAMPEL, Introdução ao direito canônico, São Paulo, LTr, 2001, pp. 64-65.
} 
estudo da apelação no direito canônico se percebe, desde a antiga legislação canônica de 1917, tal preocupação. O Novo Código de 1983 trouxe algumas mudanças relevantes no instituto da impugnação das sentenças, de forma que, ao jurista, se tornam relevantes, seja com relação ao aprimoramento da técnica, seja com a incorporação de soluções vitoriosas, mitigar a reticência havida contra o estudo da história do direito e do direito canônico. Nesse contexto, também como já dito, a apelação no direito canônico ou mesmo da atual legislação canônica constitui importante instrumento de investigação em soluções adotadas no passado ou em outros ordenamentos.

\section{Bibliografia}

ANDRIEU-GUITRANCOURT, Pierre. Principes Sociaux du Droit Canonique contemporain, Paris: Sirey, 1939.

ÁVILA CRUZ, José de. A evolução histórica do processo de nulidade matrimonial e a figura jurídica do defensor do vínculo, São Paulo, 2001, dissertação de mestrado perante a Pontifícia Faculdade de Teologia Nossa Senhora da Assunção (Instituto de Direito Canônico "Pe. Dr. Giuseppe Benito Pegoraro").

AZEVEDO, Luiz Carlos. Introdução à História do Direito, São Paulo: RT, 2005.

e CRUZ E TUCCI, José Rogério. Lições de Processo Civil Canônico, São Paulo: RT, 2001.

BAPTISTA DA SILVA, Ovídio A. Jurisdição e execução na tradição romano-canonica, 3. ed., Rio de Janeiro: Forense, 2007.

BERTOCCO, Luciana Carla Corrêa. Origens e evolução da figura do juiz, São Paulo, 2005, dissertação de mestrado perante a Pontifícia Universidade Lateranense de Roma (Instituto de Direito Canônico "Pe. Dr. Giuseppe Benito Pegoraro").

BERTOLA, Arnaldo. "Diritto Canonico”, Novissimo Digesto Italiano, vol. V, Torino: VTET, 1957.

CALAMENDREI, Piero. "Introduzione allo studio sistemático dei provvedimenti cautelari”. Opere Giuridiche, Napoli: Morano, 1983.

CARNELUTTI, Francesco. Diritto e Processo, Napoli: Morano, 1953-1958.

CONDE, Manoel J. Arroba. Direito Processual Canônico (Trad. MARTIN SEGÚ GIRONA), 5. ed., São Paulo: EDIURCA-Editiones Institutum Iuridicum Claretianum, 2006. 
CRUZ E TUCCI, José Rogério; AZEVEDO, Luiz Carlos de. Lições de Processo Civil Canônico, São Paulo: RT, 2001.

D’OSTILIO, Francesco. I Processi Canonici - Loro giusta durata, Roma: Edizioni Dehoniane, 1989.

DELLA ROCCA, Fernando. Diritto Canonico, Padova: CEDAM, 1961.

DINAMARCO, Cândido Rangel. A reforma da reforma, 4. ed., São Paulo: Malheiros, 2003. 2002.

. A instrumentalidade do processo, $10^{\mathrm{a}}$ ed., São Paulo: Malheiros, A Instrumentalidade do processo, $6^{\mathrm{a}}$ ed., Malheiros, São Paulo, 1998.

FAÍLDE, Juan José García. Nuevo Derecho Procesal Canonico, 3ª ed., Salamanca: Publicaciones Universidad Pontificia Salamanca, 1995.

FALCO, Mario. Corso di Diritto Ecclesiastico, volume primo, 2. edizione, Padova: CEDAM, 1935

FEDELE, Pio. “Diritto Canonico”, Enciclopedia del diritto, vol XII, Milano: Giuffrè, 1964.

GIGANTE, José Antônio Martins. Instituições de Direito Canônico, vol. III, 2. ed., Braga: Esc. Tip. da Oficina de S. José, 1952.

. Instituições de Direito Canônico, vol. I, 2. ed., Braga: Esc. Tip. da Oficina de S. José, 1951.

GIUNTA, G. P. Sinopoli di. Sinopsi del codice di diritto Canonico, Torino-Roma: Cav. Pietro Marietti Editre, 1920.

GOMES DA SILVA, Nuno J. Espinosa. História do Direito Português - fontes de direito, 3. ed., Lisboa: Fundação Calouste Gulbenkian, 2000.

GRAVIERS, Jean des. Le Droit Canonique, 10. édition, Paris: Presses Universitaires de France, 1967.

HORTAL, Jesús. Código de Direito Canônico (trad. Conferência Nacional dos Bispos do Brasil), 9. ed., São Paulo: Edições Loyola, 1995.

JASSONI, Massimo. Il giuramento - profili di uno studio sul processo di secolarizzazione dell'intituto nel diritto canonico, Milano: Giuffrè, 1999.

JEMOLO, Arturo Carlo. Lezioni di Diritto Ecclesiastico, 3. ed., Milano: Giuffrè, 1958.

LOMBARDÍA, Pedro. Lições de Direito Canônico, São Paulo: Loyola, 2008. ; ARRIETA, Juan Ignácio. Código de Direito Canônico - edição anotada (trad. José A. Marques), 2. ed., Braga: Tip. da Empresa do Diario do Minho, 1997. 
LUCON, Paulo Henrique dos Santos. Eficácia das decisões e execução provisória, São Paulo: RT, 2000.

MONDIN, Paola Buselli. Il sistema dei ricorsi e dei decreti nel processo matrimoniale canonico, Roma: Lateran University Press, 2004.

MOREIRA DE PAULA, Jônatas Luiz. História do Direito Processual Brasileiro, São Paulo: Manole, 2002.

NEVES, Celso. Estrutura fundamental do processo civil, Rio de Janeiro: Forense, 1995.

OLIVERO, Giuseppe. "Apello - Diritto Canonico”. Enciclopedia del diritto, vol. II, Milano: Giuffrè, 1958.

ORESTANO, Riccardo. “Appello (Diritto Romano)”, in Novissimo Digesto Italiano, Torino: VTET, 1957.

PROTO PISANI, Andrea. Lezione di diritto processuale civile. Napoli: Jovene, 1999.

REALE, Miguel. Teoria Tridimensional do Direito, 5. ed., 6. tiragem, São Paulo: Saraiva, 2003.

Lições Preliminares de Direito, 27. ed., 3. tiragem, São Paulo: Saraiva, 2003.

SAMPEL, Edson Luiz. Introdução ao direito canônico, São Paulo: LTr, 2001. "Direito processual canônico", Revista de Cultura Teológica, ano XI, n. 43, São Paulo: Paulinas, 2003.

SURGIK, Aloísio. Compêndio de Direito Processual Canônico, Curitiba: Edições Livro é Cultura, 1988.

TAMASSIA, Nino. Appunti di direitto ecclesiastico, Padova: CEDAM, 1930.

ZANOTTI, Andréa; ORLANDO, Fúlvio. L'Itinerario Canonistico di Giuseppe Caputo, Milano: Giuffrè, 2002. 